1 Dr. Khondker Saif Imtiaz MBBS, MPH, DPS

Assistant Professor

2 Prof. Dr. Nilufar Begum MBBS, MPhil (Micro) WHO, Fellow (Bangkok, Delhi) Professor \& Head Dept. of Microbiology Bangladesh Medical College, Dhaka

${ }^{3}$ Dr. Humaira Nazneen MBBS, MPH

Assistant Professor

${ }^{4}$ Dr. Nushrat Tamanna MBBS, MPH

Assistant Professor

${ }^{5}$ Dr. Samiha Naureen MBBS

Honorary Medical Officer

Dept. of Medicine

Dhaka Medical College Hospital

6 Md. Golam Kibria

B.Sc in Nursing, MPH

Lecturer, Dept. of Nursing

State College of Health Sciences, Dhaka

\section{$1,3,4$}

Dept. of Community Medicine International Medical College Gazipur

\section{Correspondence}

Dr. Khondker Saif Imtiaz

MBBS, MPH, DPS

Assistant Professor

Dept. of Community Medicine International Medical College, Gazipur E-mail: saifimtiaz105@yahoo.com

\title{
Health Education Intervention Regarding Swine Flu among Secondary School Students in a Selected School of Dhaka City
}

\author{
K S Imtiaz ${ }^{1}$ N Begum² ${ }^{2}$ H Nazneen ${ }^{3}$, N Tamanna ${ }^{4}$, S Naureen ${ }^{5}$, M G Kibria ${ }^{6}$
}

\section{Abstract}

Background : Swine flu is a viral disease spread by droplet infection during coughing, sneezing, laughing or talking. Mortality rate among the adolescent is high.

Objective : To assess the outcome of health education intervention on knowledge regarding Swine flu among adolescent students of a selected school in Dhaka city.

Material \& Methods : A quasi-experimental study was conducted among 150 students of class $\times$ of B.C.S.I.R. High School in Dhaka city. As Dhaka city is densely populated and chance of transmission Swine flu is higher.

Results : The mean age of the students was 14.83 years. Regarding educational qualification of their mothers, $40 \%$ had completed education up to the S.S.C level. In case of occupational status of the fathers, $50.7 \%$ were businessmen. A majority $(31.3 \%)$ of the respondents had monthly income of 20,001-30,000 Taka. Almost all $(99.3 \%)$ of the students had heard the name of Swine flu and their source of information was from newspapers $(50.5 \%)$ followed by that of television (26.2\%),family members (8.1\%) and radio(4.7\%). Before intervention- regarding the causative agent $\&$ mode of transmission, $75.3 \% \& 92.0 \%$ of the students had a good knowledge respectively. Fair knowledge was observed among the students regarding signs \& symptoms $(50.7 \%)$, complications $(46.0 \%)$ and preventive measures $(51.3 \%)$ of the disease. Poor knowledge was found regarding high risk groups of the disease among $52 \%$ of respondents. A high proportion of respondents, $(94.0 \%)$ had no knowledge regarding treatment of Swine flu. In case of overall knowledge regarding Swine flu, 27.3\% had poor knowledge; $56.7 \%$ had fair knowledge and $16.0 \%$ had good knowledge before intervention. After health education intervention $98.7 \%$ \& 1.37 of students had good \& fair level of knowledge regarding the disease respectively no respondent was observed poor knowledge. Chi square test $\left(x^{2}=2.096, d f=2\right)$ showed the significant association $(\mathrm{p}<0.001)$ between health education intervention and knowledge on Swine flu among the students, before \& after intervention. So all school students should be motivated well by a health education intervention programme regarding Swine flu, as they are one of the vulnerable groups of the disease

Keywords : Swine flu, Health education intervention, Secondary school students

\section{Introduction}

Swine influenza refers to influenza caused by those strains of influenza virus that usually infect pigs and are called Swine influenza virus (SIV). The 2009 flu outbreak in human that is widely known as "Swine flu" is due to a new strain of influenza A virus, subtype $\mathrm{H}_{1} \mathrm{~N}_{1}$, that was produced by reassortment from one strain of human influenza virus, one strain of avian influenza virus and two separate strains of Swine influenza virus. The potential for Swine influenza virus to cause a human flu pandemic is greater than previously thought. ${ }^{1}$ Influenza pandemic occurs when an influenza virus is efficiently transmitted from person to person against which the human population has limited immunity. An influenza pandemic has the potential to cause considerable morbidity \& mortality for a concentrated period of around 8-12 weeks with recurrence in waves over 2-3 years. $^{2}$

The history of influenza pandemic is very ancient. On an average, 3 pandemic of influenza per century have been documented since $16^{\text {th }}$ century occurring at interval of $10-50$ years. ${ }^{3}$ First documented Swine flu pandemic in human occurred in 1918. The most well known outbreak of Swine flu occurred in 1976, among the soldiers of Fort Dix, New Jersy, USA. In Phillipines, an outbreak occurred in 2007 and mortality rate was around $10 \%{ }^{4}$ Latest Swine flu pandemic of $21^{\text {st }}$ century occurred in 2009. At the time of declaration of Swine flu as global pandemic on 11th June, 2009 Bangladesh was apparently free from this health problem. The first case of Swine flu in Bangladesh was detected in an incoming traveler at the Hajrat Shah Jalal International Airport on 18 th June 2009. First reported death was on 30th August, 2009.

In our country, 1,115 cases have been identified out of which 7 laboratories confirmed patients had died. ${ }^{5}$ This figure of prevalence and mortality would be much higher, as most of the cases were not laboratory confirmed and much more unreported. Spread of Swine flu in Dhaka is $52 \%$, while outside Dhaka it is $48 \%$. Swine flu cases are found in total 21 districts. After Dhaka division, cases are high in Chittagong, Khulna \& Sylhet division, while it is less in Barisal \& Rajshahi division. ${ }^{6}$ Recently, on $17^{\text {th }}$ April, 2012, 31 students of Kurigram Nursing Training Institute were diagnosed by IEDCR as cases of Swine flu. ${ }^{7}$ Government of Bangladesh has taken enough preparations to control the spread of Swine flu and treat the affected ones.

\section{Methodology}

The main focus of the study is to assess the outcome of health education intervention on knowledge regarding Swine flu among the secondary school students of Dhaka city. The aim of health education intervention programme is to improve knowledge of secondary school students regarding Swine flu.

A quasi-experimental study has been designed for the work. Firstly, pre-intervention data has been collected with the aid of semi structured questionnaire from 150 secondary school students of 
B.C.S.I.R High School, Dhaka by following convenience sampling technique. Secondly, health education intervention programme has been conducted for 5days by dividing 150 students into 10 groups. Health education regarding Swine flu has been given by delivering lectures and then distributing leaflets on the topic. Thirdly, after 7 days of effective intervention, the same questionnaire has been given to the students, which was used during pre-intervention test and thus postintervention data has been collected. After collection, all the data has been verified in order to reduce the errors and inconsistencies. Data analysis has been performed with the aid of advance statistical analysis software, SPSS

Nine knowledge related questions, having thirty correct answers about Swine flu have been incorporated in the questionnaire While analyzing the students response about the swine flu related questions, their knowledge level have been divided into four categories by using Likert Scale in the following way:

No knowledge- Respondents who score $0 \%$ (do not give correct answer)

Poor knowledge- Respondents who score $40 \%$ (give 12 correct answers) Fair knowledge- Respondents who score 41\% - 70\% (give 13- 21 correct answers) Good knowledge- Respondents who score $>70 \%$ (give $>21$ correct answers)

\section{Results}

Table I : Socio demographic characteristics of respondents Distribution of respondents according to age

$\begin{array}{lcc}\text { Age (years) } & \text { Frequency } & \text { Percentage (\%) } \\ 14 & 47 & 31.3 \\ 15 & 84 & 56.0 \\ 16 & 17 & 11.4 \\ 17 & 2 & 1.3 \\ \text { Total } & 150 & 100.0\end{array}$

Mean $=14.83$ years, Median $=15$ years, $S D=0.673$

Distribution of respondents according to their mother's educational status Illiterate

Primary

Secondary

Higher secondary

Graduate

Post graduate

$\begin{array}{cc}4 & 2.7 \\ 20 & 13.3 \\ 60 & 40.0 \\ 37 & 24.7 \\ 23 & 15.3 \\ 6 & 4.0 \\ 150 & 100.00\end{array}$

Total

100.00

Distribution of respondents according to their father's occupational status

$\begin{array}{lcc}\text { Govt. service } & 34 & 22.7 \\ \text { Private service } & 40 & 26.6 \\ \text { Business } & 76 & 50.7 \\ \text { Total } & 150 & 100.0\end{array}$

Distribution of respondents according to their monthly family income (in Taka)

$\begin{array}{lcc}<10,000 & 22 & 14.7 \\ 10,001-20,000 & 31 & 20.7 \\ 20,001-30,000 & 47 & 31.3 \\ 30,001-40,000 & 26 & 17.3 \\ 40,001-50,000 & 18 & 12.0 \\ >50,000 & 6 & 4.0 \\ \text { Total } & 150 & 100.00\end{array}$

Mean= 29,300 Taka; Median= 25,000 Taka; SD= 22276.406

As shown in the table I, majority $84(56.0 \%)$ of the respondents belonged to 15 years of age, $47(31.3 \%)$ belonged to 14 years. The mean age group of the respondents was 14.83 years.

Regarding educational status of mother majority $60(40.0 \%)$ of respondents mother completed secondary education, $37(24.7 \%)$ completed higher secondary education, $23(15.3 \%)$ were graduate, $20(13.3 \%)$ completed primary education, $6(4.0 \%)$ were post graduate and mother of only $4(2.7 \%)$ of the respondents were illiterate.

Father's occupation showed majority $76(50.7 \%)$ of the respondents father were businessman, $40(26.6 \%)$ holds private service and the rest $34(22.7 \%)$ were Govt. service holders.

Family income of respondant, majority $47(31.3 \%)$ of the respondents had monthly family income between 20,001-30,000 Taka, 31(20.7\%) had 10,001-20,000 Taka, 26(17.3\%) had 30,001-40,000 Taka, $22(14.7 \%)$ had $<10,000$ Taka, 18(12.0\%) had 40,001-50,000 Taka and the rest $6(4.0 \%)$ of the respondents had monthly family income $>50,000$ Taka. The mean monthly family income was 29,300 Taka.

$\begin{gathered}\text { Table II : Distribution of respondents whether they have heard the } \\ \text { name of Swine flu }\end{gathered}$
$\begin{array}{ccc}\text { Have heard the name of Swine flu } & \text { Frequency } & \text { Percentage (\%) } \\ \text { Yes } & 149 & 99.3 \\ \text { No } & 1 & 0.7 \\ \text { Total } & 150 & 100.00\end{array}$

As shown in the table II, almost all $149(99.3 \%)$ of the respondents have heard the name of Swine flu, expect $1(0.7 \%)$, who did not hear the name of Swine flu

Figure 1 Bar diagram showing the distribution of respondents about the source of information regarding Swine flu

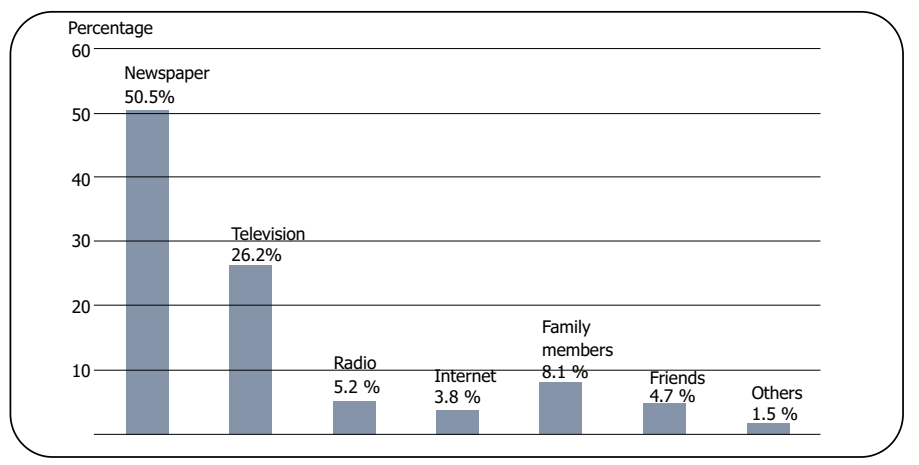

In figure 1 bar diagram showing that, from Newspaper most 76(50.5\%) of the respondents got the information regarding Swine flu while $39(26.2 \%)$ from Television, $12(8.1 \%)$ from family members, $8(5.2 \%)$ from Radio, $7(4.7 \%)$ from friends, $6(3.8 \%)$ from Internet and $2(1.5 \%)$ got the information regarding Swine flu from other sources.

Table III : Level of knowledge on swine flu before $\&$ after intervention

Causative agent of swine flue

\begin{tabular}{lcccc} 
Level of knowledge & \multicolumn{2}{c}{ Before Intervention } & \multicolumn{2}{c}{ After Intervention } \\
& Frequency & Percentage (\%) & Frequency & Percentage (\%) \\
No knowledge & 37 & 24.7 & 5 & 3.3 \\
Good knowledge & 113 & 75.3 & 145 & 96.7 \\
Total & 150 & 100.00 & 150 & 100.00
\end{tabular}

Mode of transmission of Swine flu

$\begin{array}{lcccc}\text { No knowledge } & 12 & 8.0 & 0 & 0.0 \\ \text { Good knowledge } & 138 & 92.0 & 150 & 100.0 \\ \text { Total } & 150 & 100.00 & 150 & 100.00\end{array}$

As shown in the table III, regarding causative agent of Swine flu, $37(24.7 \%)$ respondents had no knowledge while $113(75.3 \%)$ had good knowledge before intervention. After giving health education intervention, the level of good knowledge increased $96.7 \%$ of students.

Regarding mode of transmission $138(92.0 \%)$ respondents had good 
knowledge and $12(8.0 \%)$ had no knowledge. After giving intervention it had been shown that, all $150(100 \%)$ the respondents had good knowledge.

\section{Table IV : Level of knowledge on swine flu before \& after intervention} Causative agent of swine flue

\section{signs \& symptoms of Swine flu}

\begin{tabular}{lcc} 
Level of knowledge & \multicolumn{2}{c}{ Before Intervention } \\
& Frequency & Percentage (\%) \\
No knowledge & 3 & 2.0 \\
Poor knowledge & 36 & 24.0 \\
Fair knowledge & 76 & 50.7 \\
Good knowledge & 35 & 23.3 \\
Total & 150 & 100.00
\end{tabular}

\begin{tabular}{cc}
\multicolumn{2}{c}{ After Intervention } \\
Frequency & Percentage (\%) \\
0 & 0.0 \\
3 & 2.0 \\
7 & 4.7 \\
140 & 93.3 \\
150 & 100.00
\end{tabular}

\section{Complications of Swine flu}

$\begin{array}{lcccc}\text { No knowledge } & 2 & 1.3 & 0 & 0 \\ \text { Poor knowledge } & 33 & 22.0 & 1 & 0.6 \\ \text { Fair knowledge } & 69 & 46.0 & 5 & 3.4 \\ \text { Good knowledge } & 46 & 30.7 & 144 & 96.0 \\ \text { Total } & 150 & 100.00 & 150 & 100.00\end{array}$

\begin{tabular}{lcccc}
\multicolumn{7}{l}{ Preventive measures of Swine flu } \\
No knowledge & 5 & 3.3 & 0 & 0.0 \\
Poor knowledge & 68 & 45.4 & 1 & 0.6 \\
Fair knowledge & 77 & 51.3 & 3 & 2.0 \\
Good knowledge & 0 & 0.0 & 146 & 97.4 \\
Total & 150 & 100.00 & 150 & 100.00
\end{tabular}

\section{High risk groups of Swine flu}

$\begin{array}{lcccc}\text { No knowledge } & 6 & 4.0 & 0 & 0.0 \\ \text { Poor knowledge } & 78 & 52.0 & 3 & 2.0 \\ \text { Fair knowledge } & 34 & 22.7 & 6 & 4.0 \\ \text { Good knowledge } & 32 & 21.3 & 141 & 94.0 \\ \text { Total } & 150 & 100.00 & 150 & 100.00 \\ \text { Treatment of Swine flu } & & & \\ \text { No knowledge } & 141 & 94.0 & 8 & 5.3 \\ \text { Good knowledge } & 9 & 6.0 & 142 & 94.7 \\ \text { Total } & 150 & 100.00 & 150 & 100.00\end{array}$

In the table IV Lavel of knowledge on signs \& symptoms of diseases $3(2.0 \%)$ respondents had no knowledge, 36(24.0\%) had poor knowledge, 35(23.3\%) had good knowledge and 76(50.7\%) had fair knowledge regarding signs \& symptoms of Swine flu before intervention. After giving intervention, the level of good knowledge increased 140 of respondents (93.3\%).

Knowledge on complications of the disease $2(1.3 \%)$ respondents had no knowledge, 33(22.0\%) had poor knowledge, 69(46.0\%) had fair knowledge and 46(30.7\%) had good knowledge regarding complications of Swine flu before intervention. The good level of knowledge increased $96.0 \%$ after giving intervention.

Knowledge regarding preventive measures of disease $5(3.3 \%)$ respondents had no knowledge, 68(45.4\%) had poor knowledge, $77(51.3 \%)$ had fair knowledge about preventive measures of Swine flu before intervention. No respondents had good knowledge in this matter before intervention. After giving health education intervention, poor knowledge had been reduced to $0.6 \%$ of respondents while good level of knowledge increased $97.4 \%$ of them.

Knowledge on high risk groups of the disease $6(4.0 \%)$ respondents had no knowledge, $78(52.0 \%)$ had poor knowledge, $34(22.7 \%)$ had fair knowledge, while $32(21.3 \%)$ had good knowledge regarding high risk groups of Swine flu before intervention. After giving health education intervention, $141(94.0 \%)$ respondents acquired good knowledge regarding high risk groups of the disease.

Knowledge regarding treatment of disease $141(94.0 \%)$ respondents had no knowledge in contrast to only $9(6.0 \%)$ respondents had good knowledge regarding treatment of Swine flu before intervention. After intervention, the good level of knowledge had risen $94.7 \%$ of cases.

Table V : Relationship between overall level of knowledge regarding Swine flu, before $\&$ after health education intervention

\begin{tabular}{lcccc} 
Level of knowledge & \multicolumn{2}{c}{ Before Intervention } & \multicolumn{2}{c}{ After Intervention } \\
& Frequency & Percentage (\%) & Frequency & Percentage (\%) \\
Poor knowledge & 41 & 27.3 & 0 & 0.0 \\
Fair knowledge & 85 & 56.7 & 2 & 1.3 \\
Good knowledge & 24 & 16.0 & 148 & 98.7 \\
Total & 150 & 100.00 & 150 & 100.00
\end{tabular}

$\mathrm{X}^{2}=2.096, \quad \mathrm{df}=2, \quad \mathrm{p}<0.001$

Table $\mathrm{V}$ shows the relationship between overall level of knowledge regarding Swine flu, before \& after health education intervention. Before intervention, it was found that $24(16.0 \%)$ respondents had overall good level of knowledge followed by 41 (27.3\%) had poor knowledge and $85(56.7 \%)$ had fair knowledge regarding Swine flu. After giving health education intervention, overall good level of knowledge had been increased $98.7 \%$ of respondents, fair knowledge had been reduced $1.3 \%$ of them while no respondent had poor knowledge regarding Swine flu. Chi square test $\left(X^{2}=2.096, d f=2\right)$ showed the significant association $(p<0.001)$ between health education intervention and knowledge on Swine flu among the students, before \& after intervention.

\section{Discussion}

The present study was conducted among 150 students of class $X$ in B.C.S.I.R High School, Dhaka to assess the level of knowledge of the students regarding Swine flu and to find out the effectiveness of health education intervention, at the end of the study. In this study, the mean age group of the respondents was 14.83 years. A study published in Journal of American Medical Association in October, 2009 said that severe disease and mortality of 2009 Swine flu outbreak was concentrated in adolescents and adults ${ }^{8}$. As adolescents (10-19 years) have been found to be vulnerable to develop Swine flu, it is very much necessary to find out their level of knowledge. So, inclusion of this age group in the study was relevant and justified.

Regarding educational status of mother nearly all mothers were educated only 2.7 were illiterate. Occupational status, majority $76(50.7 \%)$ of the respondents father were businessmen, $40(26.6 \%)$ had private services and the rest $34(22.7 \%)$ were government service holders. In respect of monthly family income, majority $47(31.3 \%)$ of the respondents had monthly family income between 20,001-30,000 Taka, 31(20.7\%) had 10,001-20,000 Taka, 26(17.3\%) had 30,00140,000 Taka, 22(14.7\%) had <10,000 Taka, 18(12.0\%) had 40,00150,000 Taka and the rest $6(4.0 \%)$ of the respondents had monthly family income $>50,000$ Taka. In average, monthly family income was 29,300 Taka. So in overall, majority of the respondents came from a middle class family and a small percentage from affluent society.

It had been observed in the study that, almost all $149(99.3 \%)$ of the respondents have heard the name of Swine flu, expect $1(0.7 \%)$, who did not hear the name. About the sources of information, major source of information was from newspaper $(50.5 \%)$, in contrast to television $(26.2 \%)$ from where source of information was relatively low. This may 
be explained by the inadequate coverage of Swine flu in visual media. Media plays an important role for coverage on Swine flu although American people are less confident in media's ability to accurately report on Swine flu, a study ${ }^{9}$ revealed.

It had been observed that, regarding causative agent of Swine flu, $37(24.7 \%)$ respondents had no knowledge while $113(75.3 \%)$ had good knowledge before intervention. After giving health education intervention, the level of good knowledge had been increased $96.7 \%$ of students. In case of mode of transmission, $138(92.0 \%)$ respondents had good knowledge and $12(8.0 \%)$ had no knowledge before intervention but after giving intervention, all 150(100\%) the respondents had acquired good knowledge. So it had been found that majority of the students correctly knew about mode of transmission of the disease before intervention. This good knowledge has significant importance for their personal protection, as under age of 18 are most likely to get Swine flu- revealed by a study ${ }^{10}$ conducted by Imperial College, London researchers and a team from UK.

In most of the cases, Swine influenza causes a mild, uncomplicated flu like illness identical to regular seasonal influenza. After giving intervention; poor knowledge reduced $2 \%$ of students, fair knowledge reduced $4.7 \%$ of students and the level of good knowledge increased $93.3 \%$ of respondents. After giving health education intervention regarding high risk of swine flu, $141(94.0 \%)$ respondents acquired good knowledge about high risk groups of the disease. In a study ${ }^{11}$ published in September 2009 by Pew Research Centre for The People \& The Press, USA revealed that, $67 \%$ of people in USA had good knowledge in this respect, which is much higher than this study.

The range of complications of Swine flu are likely to be similar to those of seasonal influenza. In this regard the good level of knowledge increased $96.0 \%$ of students after giving intervention. This revealed the importance of health education intervention to increase the knowledge. Although flu medicin's effectiveness is somewhat limited, studies ${ }^{12}$ have shown, they can relieve symptoms and shorten the disease by about a day \& only work if started within 48 hours of first symptoms. About the anti-viral treatment, it had been found in this study that, 141(94.0\%) respondents had no knowledge in contrast to only $9(6.0 \%)$ respondents, who had good knowledge regarding treatment of Swine flu before intervention. After intervention, the good level of knowledge had risen to $94.7 \%$ of cases.

Personal protection is a prime requisite to prevent Swine flu. It had been observed in the study that no respondent had good knowledge in this matter before intervention. After giving health education intervention, poor knowledge had been reduced $0.6 \%$ of respondents while good level of knowledge increased $97.4 \%$ of them. A telephone survey's report ${ }^{13}$ among 997 adults of London in May, 2009 regarding behavioral changes for prevention of Swine flu, conducted by researchers at Institute of Psychiatry King's College London and the Health Protection Agency revealed that $72 \%$ people had not changed the frequency of their hand washing while $83 \%$ had not increased the amount that they cleaned or disinfected things. So behavioural changes for prevention of Swine flu were limited in spite of high mass media coverage in USA. So it might be concluded that, although from this study, $97.4 \%$ of students had acquired good level of knowledge regarding preventive measures of Swine flu after health education intervention, this knowledge must be transformed into daily behavioural practice for prevention of the disease.

At last, overall level of knowledge regarding Swine flu was categorized into- poor knowledge, fair knowledge and good knowledge. From this study, it had been revealed that- $41(27.3 \%)$ respondents had poor knowledge; $85(56.7 \%)$ had fair knowledge and only $24(16.0 \%)$ had overall good knowledge regarding Swine flu before intervention. After health education intervention, the overall good level of knowledge regarding the disease had increased to $98.7 \%$ of students; fair knowledge reduced to $1.3 \%$ of them and no respondents was observed with poor knowledge. Chi square test $\left(x^{2}=2.096, d f-2\right)$ done and result showed the significant association $(p<0.001)$ between health education intervention and knowledge on Swine flu among the students, before \& after intervention. This data reflects the importance of health education programmes for increasing the knowledge regarding Swine flu among school students.

\section{Conclusion}

Swine flu is a preventable emerging disease. Bangladesh is a densely populated country with poor literacy rate. High disease incidence in neighboring countries, overcrowded population, lack of awareness and poor practice of personal hygiene poses our country in risky situation of Swine flu. In this study overall knowledge of secondary school students on swine flu, majority of the respondents had poor to fair knowledge, while only a small percentage had good knowledge regarding Swine flu before intervention. After health education intervention, almost all of the students developed good level of knowledge regarding various aspects of Swine flu. Chi square test showed the significant association between health education intervention and improvement of knowledge regarding the disease among the students.

Therefore, sufficient information on Swine flu should be included in the national curriculum for school students to increase their knowledge and they should be motivated well by a health education intervention programme regarding the disease. It can be concluded that, public awareness should be raised regarding Swine flu through health education programmes and mass media communication, without creating undue panic about the disease.

\section{References}

1. Denial $R$ Parez. Minimal molecular constraints for respiratory droplet transmission of an avainhuman $\mathrm{H}_{9} \mathrm{~N}_{2}$ influenza A virus, Proceeding of the National Academy of Sciences. 2009

2. Swine influenza- wikipedia, the free encyclopedia. 2009, http:// en. wikipedia. org/ wiki/ Swine influenza.

3. Heinen PP. History of Swine flu pandemic. 2009; http;//www.pubmedcentral.nih.com

4. Center for Disease Control \& Prevention.2009; http;//www.cdc.gov

5. Global alert response (GAR)-WHO/pandemic $\left(\mathrm{H}_{1} \mathrm{~N}_{1}\right)$, update 84

6. Institute of Epidemiology, Disease Control \& Research (I.E.D.C.R). 29 th June, 2010.

7. Bangladesh on alert to prevent Swine flu after citizen dies in Mexico, 2009. www.China view.com

8. Swine Flu Research: $H_{1} N_{1}$ mostly affects younger patients, can turn critical quickly. Journal of American Medical Association.2009

9. Public Aware of Key Swine Flu Facts: Summary of findings- Pew Research Center for the People \& the Press. September $32009 ; 3-4$

10. Imperial College, London research. Published in New England Journal of Medicine. 2009

11. Public Aware of Key Swine Flu Facts: Summary of findings- Pew Research Center for the People \& the Press. September 3 2009; 5

12. Question \& Answers: Anti-viral drug, Flu season CDC, USA.2010; 3; http;//www.cdc.gov; $\mathrm{h}_{1} \mathrm{n}_{1}$ flu/ antiviral.htm

13. British Medical Journal Website. Retrieved May 14, 2010; http;//www. Science Daily.com 